\title{
Strength Effect of Different U-Shaped HDR Thicknesses in Hook-End Precast Beam- Column Joint: A Nonlinear FE Analysis
}

\author{
Kai Siong Woon ${ }^{1 *}$ and Farzad Hejazi $^{2}$ \\ ${ }^{1}$ Lee Kong Chian Faculty of Engineering and Science, Universiti Tunku Abdul Rahman, Jalan Sungai \\ Long, Bandar Sungai Long, Cheras, 43000 Kajang, Selangor, Malaysia \\ ${ }^{2}$ Department of Civil Engineering, Faculty of Engineering, Universiti Putra Malaysia, 43400 UPM \\ Serdang, Selangor, Malaysia
}

\begin{abstract}
A precast reinforced concrete frame constructed with new hook-end joint at both beam-column connections was numerical modelled and analysed using Finite Element Method, for its overall strength attainment under the action of horizontal cyclic loading. Five different thicknesses of U-shaped HDR, ranging from 15 to $35 \mathrm{~mm}$ thick in $5-\mathrm{mm}$ intervals, were assigned in the numerical model as the vibrational absorber component in between the hook-end beam-column joints. The numerical force-displacement curves showed that precast frame with various thicknesses of U-shaped HDR had similar shape of hysteresis loops among each other. However, the precast frame with $25 \mathrm{~mm}$ thick of U-shaped HDR at its hook-end beam-column joint demonstrated the capacity to fulfil the highest force and displacement demands when compared with other thicknesses of HDR.
\end{abstract}

\section{Introduction}

High damping rubber (HDR) has been commonly being used as one of the damper materials at the foundation or connection of building structures [1-3] in seismic area and bearing of bridge girders. It is because HDR, as one of the viscoelastic material offers the advantage of reducing vibrations over a broad range of frequencies compared with tuned mass damper [4]. Furthermore, the use of viscoelastic materials is a cheap method to increase the damping of a structure if incorporated during construction [5]. However, the cyclic performance of a structure equipped with rubber damper may be affected by its thickness, other than the structural configuration and material properties of HDR. It is because sufficient thickness of rubber provides adequate deformation space and stiffness between the connected members [6]. Therefore, it can prevent serious local damage of concrete at the interspace between the connecting members.

Lu et al. [6] utilized $50 \mathrm{~mm}$ thick of rubber blocks to prevent local failure of concrete at the interspace between the precast prestressed column and base. Xing et al. [7] conducted

\footnotetext{
*Corresponding author: woonks@utar.edu.my
} 
dynamic stability study on various rubber damper thicknesses with shape factors ranging from 3.75 to 7.5 , and found that instability in individual rubber bearings does not necessarily lead to global system instability. However, Banisheikholeslami et al. [3] found no sensible change in behavior of the steel beam-column connection equipped with different rubber damper thickness. It is because the opposing effects from the reduction of shear strain in thicker rubber layer and the increment of dissipated energy due to larger volume of thicker rubber, neutralize each other. Therefore, in this paper, the effect of HDR thickness in the newly developed hook-end joint is investigated in order to determine its optimum cyclic performance to a precast reinforced concrete frame structure.

\section{Description of specimen}

In this study, a precast reinforced concrete frame with dimensions of $2.3 \mathrm{~m} \times 1.905 \mathrm{~m}$ was constructed with hook-end joint at both ends of precast beam and corbels. The hook-end configuration was intended to provide an interlocking mechanism between the precast beam and column components whilst maintaining the ease of installation, structural stability and integrity of the precast structure. The gap between the two hook-end components was filled with U-shaped HDR to provide some degree of translation and rotational restraints to the connected members under the action of cyclic loading. In addition, it reduces the potential points of impact and concrete crushing between the members.

Fig. 1 illustrates the reinforcement detail of the precast frame with hook-end beamcolumn joints. Both precast columns were in fixed connection at the bottom. A $500 \mathrm{~kg}$ of additional weight was loaded on top of the precast beam to simulate slab loading to the beam, as shown in Fig. 2. Displacement based cyclic loading was exerted at the mid span of the precast beam with its load profile illustrated in Fig. 3 according to ACI T1.1-01 [8].

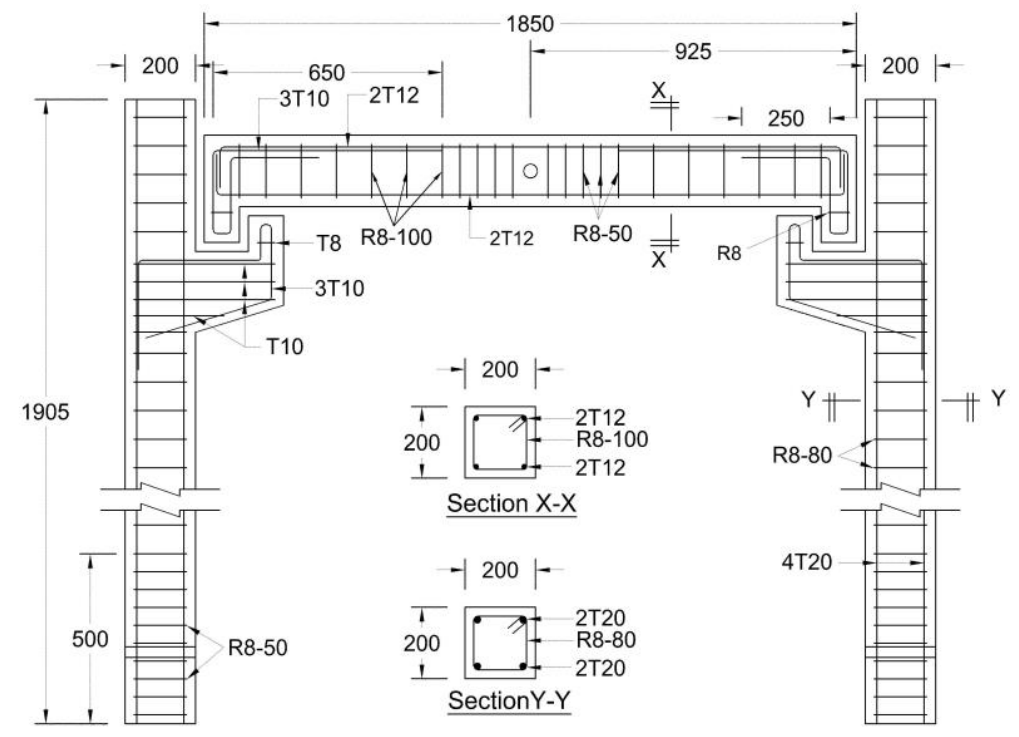

Fig. 1. Reinforcement detailing of precast frame with U-shaped HDR beam-column joint. 


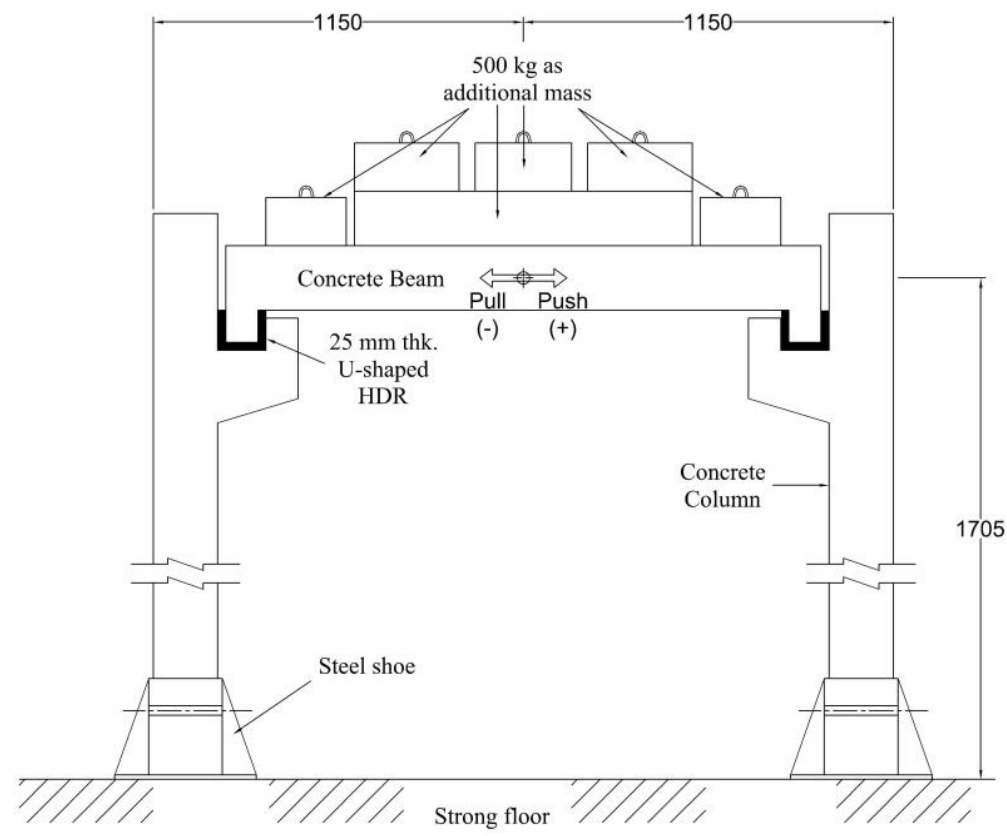

Fig. 2. Tests setup for precast frame with U-shaped HDR beam-column joint.

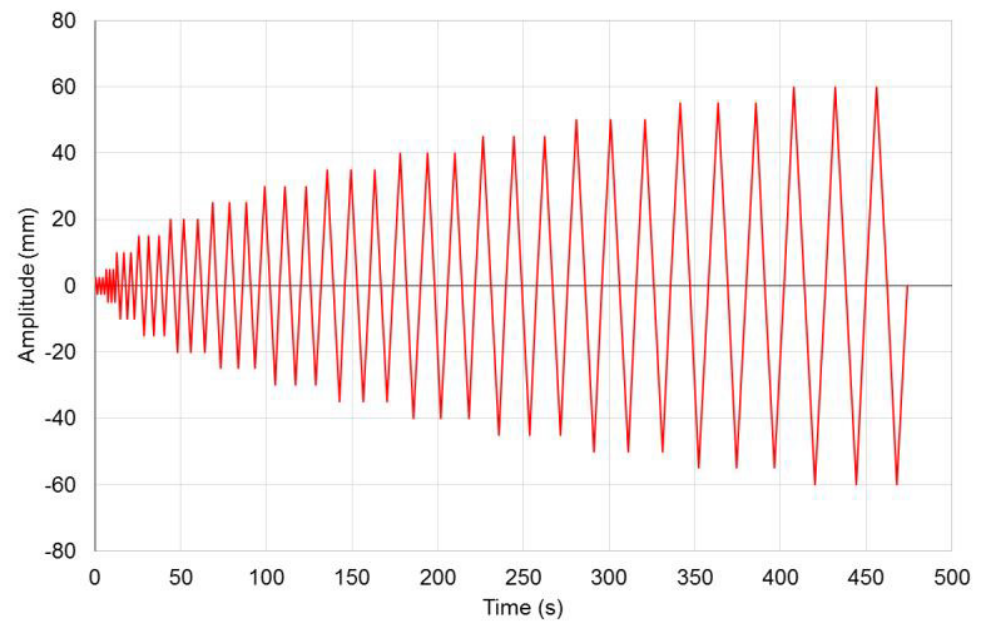

Fig. 3. Load profile of horizontal cyclic test [8]

\section{Numerical modelling}

A numerical model for precast frame with hook-end U-shaped HDR beam-columns joints, was developed using ABAQUS finite element analysis (FEA) software. Five different thicknesses of U-shaped HDR, ranging from $15 \mathrm{~mm}$ to $35 \mathrm{~mm}$ thick were involved in the numerical analysis. Table 1 lists the designated name of the numerical specimen. 
Table 1. Numerical specimen name with its respective HDR thickness

\begin{tabular}{|c|c|c|c|c|c|}
\hline Numerical specimen & NU-01 & NU-02 & NU-03 & NU-04 & NU-05 \\
\hline $\begin{array}{c}\text { Thickness of U-shaped } \\
\text { HDR (mm) }\end{array}$ & 15 & 20 & 25 & 30 & 35 \\
\hline
\end{tabular}

\subsection{Material properties and types of element}

The beam and column components were assigned with concrete C25/30 material using Concrete Damage Plasticity Model [9] to simulate its nonlinearity behaviour. The density, Young's modulus and Poisson ratio of the concrete were taken as $2500 \mathrm{~kg} / \mathrm{m}^{3}, 26.4 \mathrm{GPa}$ and 0.2 , respectively. The compressive and tensile stress-strain relationships for concrete C25/30 were derived based on Hsu and Hsu model [10] and Wahalathantri et al. [11]. Classical Plastic Model was used to model the steel reinforcement. Table 2 summarises the properties of steel reinforcement used in the numerical modelling. The properties of HDR identified by Marshall [12] were adopted.

Both beam and columns were modelled in C3D8R elements (8-node linear bricks with reduced integration). The U-shaped HDR was modelled in C3D8RH elements (8-node linear bricks with reduced hybrid integration). The steel reinforcement was modelled by T3D2 elements (2-node linear 3D truss).

Table 2. Properties of steel reinforcement

\begin{tabular}{|c|c|c|c|c|c|}
\hline $\begin{array}{c}\text { Steel } \\
\text { grade }\end{array}$ & $\begin{array}{l}\text { Density } \\
\left(\mathrm{kg} / \mathrm{m}^{3}\right)\end{array}$ & $\begin{array}{l}\text { Young modulus, } \\
\mathrm{E}\left(\mathrm{kN} / \mathbf{m m}^{2}\right)\end{array}$ & $\begin{array}{l}\text { Poisson } \\
\text { ratio, } v\end{array}$ & $\begin{array}{c}\text { Yield stress } \\
\left(\mathbf{N} / \mathbf{m m}^{2}\right)\end{array}$ & $\begin{array}{l}\text { Plastic } \\
\text { strain }\end{array}$ \\
\hline $\begin{array}{c}\text { High yield } \\
\text { steel }\end{array}$ & \multirow{2}{*}{7850} & \multirow{2}{*}{200,000} & \multirow{2}{*}{0.3} & $\begin{array}{l}400 \\
460\end{array}$ & $\begin{array}{c}0 \\
0.156\end{array}$ \\
\hline Mild steel & & & & $\begin{array}{l}200 \\
250\end{array}$ & $\begin{array}{c}0 \\
0.13\end{array}$ \\
\hline
\end{tabular}

\subsection{Interaction properties}

Embedded element was selected to model the non-slip reinforcement condition at the interaction between the concrete and steel reinforcement. Meanwhile, the interaction between the U-shaped HDR and concrete surfaces was defined with a friction coefficient value of 0.59 in the tangential direction.

\subsection{Finite element mesh sizes}

All the components in the numerical model were meshed using the structured and free meshing technique. For beam and column components, mesh sizes of $50 \mathrm{~mm} \times 50 \mathrm{~mm} \times 50$ $\mathrm{mm}$ were assigned in all regions, except at regions subjected to more tensile cracking and tremendous strain changes, where mesh sizes of $25 \mathrm{~mm} \times 50 \mathrm{~mm} \times 50 \mathrm{~mm}$ were assigned. Mesh sizes of $5 \sim 12 \mathrm{~mm} \times 25 \mathrm{~mm} \times 25 \mathrm{~mm}$ were used to assigned to represent the Ushaped HDR.

\section{Numerical results}

The strength effect of $15 \mathrm{~mm}, 20 \mathrm{~mm}, 25 \mathrm{~mm}, 30 \mathrm{~mm}$ and $35 \mathrm{~mm}$ thickness of U-shaped HDR to the hook-end precast frame under the horizontal cyclic loadings, were numerically 
analysed. The numerical analysis on the horizontal cyclic load test stopped when more than $20 \%$ of strength degradation was observed [13] or due to convergence problem aroused.

The force-displacement loops of each numerical specimen are presented in Fig. 4. It can be seen that the shape of the hysteresis loops are similar among each numerical specimen although different U-shaped HDR thicknesses were assigned in the analysis. Fig. 5 plots the force-displacement envelope for the numerical specimens and Table 3 tabulates their corresponding maximum force and displacement at the maximum force. It can be seen that minor differences were found between their force-displacement performance. However, the $25 \mathrm{~mm}$ thick U-shaped HDR provides the highest maximum force when compared with specimens of other thicknesses.

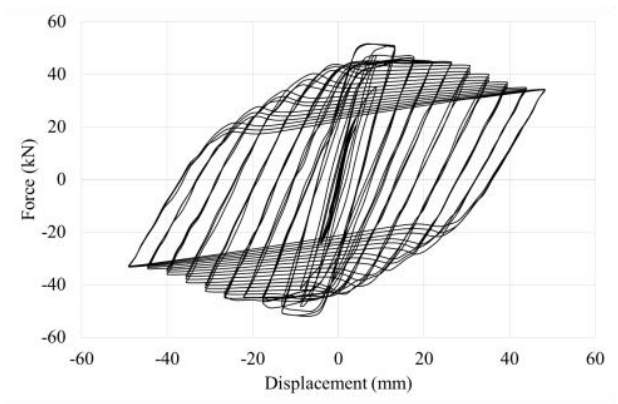

(a) NU-01

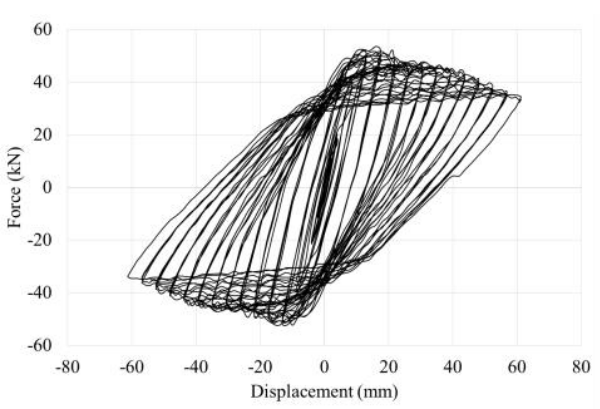

(c) NU-03

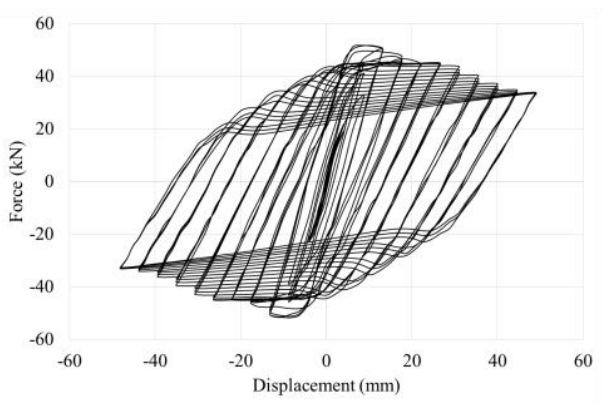

(b) NU-02

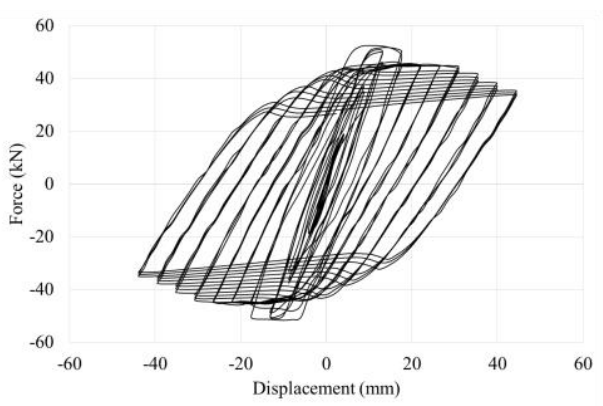

(d) NU-04

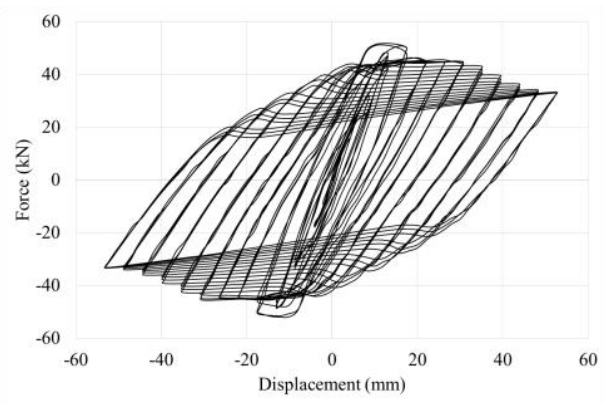

(e) NU-04

Fig. 4. Force-displacement diagram for numerical specimens with different thickness of U-shaped HDR 


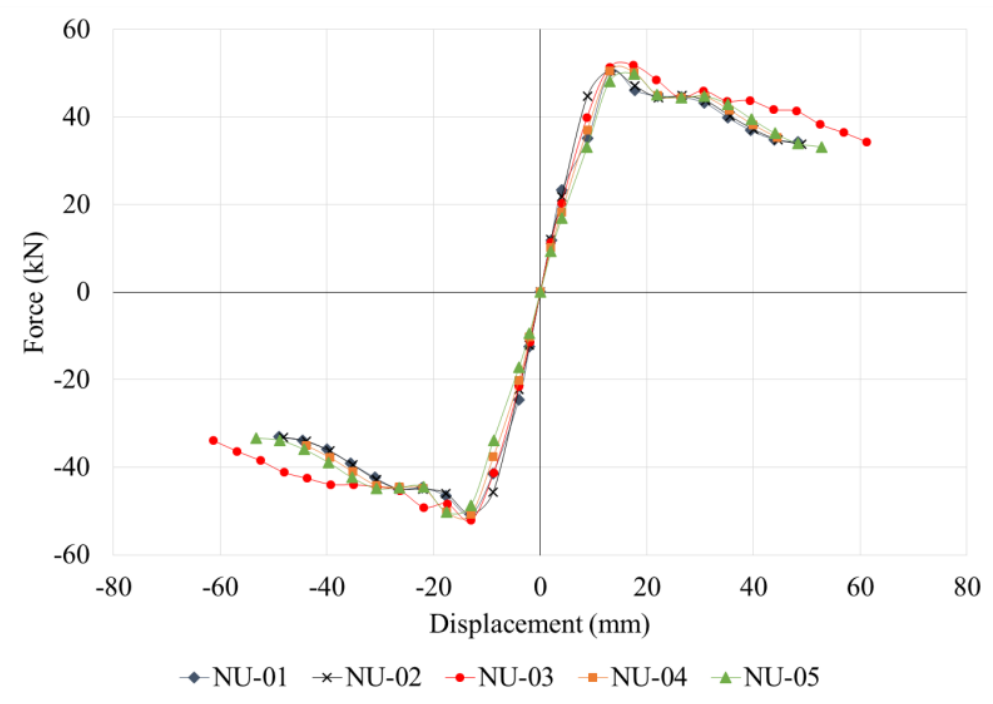

Fig. 5. Force-displacement envelope for numerical specimens with different thickness of U-shaped HDR

Table 3 also lists the normalized maximum force for each U-shaped HDR, $F_{\max }$ with respect to the corresponding maximum force for $25 \mathrm{~mm} \mathrm{U}$-shaped HDR thick, $F_{\max , u}$. It can be seen that $25 \mathrm{~mm}$ thick of U-shaped HDR pad exhibits a 3\% to $5 \%$ higher maximum strength than specimens of other HDR thickness. The phenomenon of thicker U-shaped HDR rubber in the hook-end beam-column joint has decreasing strength is similar to the parametric study by Kremmyda et al. [14]. However, the numerical results do not tally with Kremmyda et al. [14] when thinner U-shaped HDR pads were used. This is probably due to the hook-end connection not utilizing any dowel bar at the precast beam-column joint to achieve the shear strength. Whereas, the strength of the precast reinforced concrete frame studied in this research is depending on the hook-end connection system, which utilized Ushaped HDR as the vibration absorber component.

Table 3. The maximum force and maximum displacement of numerical specimens with different Ushaped HDR thicknesses.

\begin{tabular}{|c|c|c|c|c|c|c|}
\hline \multirow[t]{2}{*}{$\begin{array}{c}\text { Numerical } \\
\text { specimen }\end{array}$} & \multicolumn{2}{|c|}{$\begin{array}{c}\text { Maximum force, } F_{\max } \\
(\mathrm{kN})\end{array}$} & \multicolumn{2}{|c|}{$\begin{array}{c}\text { Displacement at } F_{\max }, \\
\operatorname{\Delta max}(\mathrm{mm})\end{array}$} & \multicolumn{2}{|c|}{$\begin{array}{l}\text { Normalized maximum } \\
\quad \text { force, } F_{\max } / F_{\max , u}\end{array}$} \\
\hline & Push & Pull & Push & Pull & Push & Pull \\
\hline NU-01 & 50.51 & -50.78 & 13.13 & -13.13 & 0.962 & 0.975 \\
\hline NU-02 & 50.71 & -50.69 & 13.11 & -13.12 & 0.966 & 0.973 \\
\hline NU-03 & 52.50 & -52.09 & 14.75 & -13.00 & 1.000 & 1.000 \\
\hline NU-04 & 50.59 & -50.75 & 13.06 & -13.05 & 0.964 & 0.974 \\
\hline NU-05 & 49.90 & -50.27 & 17.56 & -17.56 & 0.950 & 0.965 \\
\hline
\end{tabular}

\section{Conclusion}

The strength effect of five different thicknesses of U-shaped HDR, ranging from $15 \mathrm{~mm}$ to $35 \mathrm{~mm}$ with $5 \mathrm{~mm}$ of interval thickness, for precast hook-end beam-column joint were analysed numerically and evaluated. The specimens yielded approximately similar force- 
displacement hysteresis curves among each other. Under the application of horizontal cyclic loading, the $25 \mathrm{~mm}$ thick U-shaped HDR specimen yields approximately $3 \% \sim 5 \%$ and $20 \% \sim 25 \%$ higher strength than the precast frame that adopted the other U-shaped HDR thickness.

This work received financial supports from the University Putra Malaysia under PUTRA GRANT No. 9606600 and Universiti Tunku Abdul Rahman. The supports are gratefully acknowledged.

\section{References}

1. F. Tomoki, N. Masato, ATC \& SEI 2009 Conference on Improving the Seismic Performance of Existing Buildings and Other Structures (San Francisco, California, 2009)

2. T. Guo, W. Xu, L. Song, L. Wei, J. Perform. Constr. Facil. 28, 96-107 (2014)

3. A. Banisheikholeslami, F. Behnamfar, M, Ghandil, J. Constr. Steel Res. 117, 185 (2016)

4. I. Saidi, E.F. Gad, J.L. Wilson, N. Haritos, Eng. Struct. 33, 3317 (2011)

5. F. Ljunggren, A. Agren, App. Acoustic. 63, 1267 (2002)

6. X. Lu, Y. Cui, J. Liu, W. Gao, Earthquake Eng. Struct. Dyn. 44, 1899 (2015)

7. H. Xing, P.W. Gordon, K. Amarnath, Structure Congress 2013: Bridging Your Passion with Your Profession (Pittsburgh, Pennsylvania, 2013)

8. ACI T1.1-01, Acceptance criteria for moment frames based on structural testing, (American Concrete Institute, Farmington Hills, 2001)

9. ABAQUS Theory Manual, version 6.11-3, Dassault Systemes (2011)

10. L.S. Hsu and C.T. Hsu, ACI Struct J, 91, 448 (1994)

11. B.L. Wahalathantri, D.P. Thambiratnam, T.H.T. Chan, S. Fawzia, 1st International Postgraduate Conference on Engineering, Designing and Developing the Built Environment for Sustainable Wellbeing (eddBE, Australia, 2012)

12. J.D. Marshall, Development, Analysis and Testing of a Hybrid Passive Control Device for Seismic Protection of Framed Structures (2008)

13. G.D. Kremmyda, Y.M. Fahjan, S.G. Tsoukantas, Bull. Earthquake Eng. 12, 1615 (2014)

14. G.D. Kremmyda, Y.M. Fahjan, S.G. Tsoukantas, Earthquake Eng. \& Struct. Dyn. (2017) 